\title{
Social structure varies with elevation in an Alpine ant
}

\author{
JESSICA PURCELL, ${ }^{1}$ LOÏC PELLISSIER ${ }^{2}$ and MICHEL CHAPUISAT \\ Department of Ecology and Evolution, University of Lausanne, Biophore, UNIL-Sorge, Lausanne 1015, Switzerland
}

\begin{abstract}
Insect societies vary greatly in social organization, yet the relative roles of ecological and genetic factors in driving this variation remain poorly understood. Identifying how social structure varies along environmental gradients can provide insights into the ecological conditions favouring alternative social organizations. Here, we investigate how queen number variation is distributed along elevation gradients within a socially polymorphic ant, the Alpine silver ant Formica selysi. We sampled low- and high-elevation populations in multiple Alpine valleys. We show that populations belonging to different drainage basins are genetically differentiated. In contrast, there is little genetic divergence between low- and high-elevation populations within the same drainage basin. Thus, elevation gradients in each of the drainage basins represent independent contrasts. Whatever the elevation, all well-sampled populations are socially polymorphic, containing both monogynous (= one queen) and polygynous (= multiple queen) colonies. However, the proportion of monogynous colonies per population increases at higher elevation, while the effective number of queens in polygynous colonies decreases, and this pattern is replicated in each drainage basin. The increased prevalence of colonies with a single queen at high elevation is correlated with summer and winter average temperature, but not with precipitation. The colder, unpredictable and patchy environment encountered at higher elevations may favour larger queens with the ability to disperse and establish incipient monogynous colonies independently, while the stable and continuous habitat in the lowlands may favour large, fast-growing polygynous colonies. By highlighting differences in the environmental conditions favouring monogynous or polygynous colonies, this study sheds light on the ecological factors influencing the distribution and maintenance of social polymorphism.
\end{abstract}

Keywords: altitude, climate, formicinae, range limit, social evolution, social polymorphism

Received 16 September 2014; revision received 21 November 2014; accepted 26 November 2014

\section{Introduction}

Animal societies exhibit tremendous diversity in their social organization, both within and among species, and understanding the causes of this variation can shed light on the basic principles of social evolution (Bourke 2011). The social structure of groups is determined by

Correspondence: Jessica Purcell, Fax: +41 2169241 65;

E-mail: Jessica.Purcell@unil.ch

${ }^{1}$ Present address: Department of Entomology, University of California, Riverside, 900 University Avenue, Riverside, CA 92521, USA

${ }^{2}$ Present address: Department of Biology, University of Fribourg, Chemin du Musée 10, Fribourg 1700, Switzerland the number of breeders, which shapes the distribution of genetic diversity within and among social groups, and thus profoundly influences cooperation, conflicts and social evolution (Hughes et al. 2008a; Keller 1995b; Ross 2001). Although species vary greatly in the number of breeders per group, the mechanisms and selective pressures contributing to the evolution and maintenance of alternative social structures remain poorly understood. By investigating how social structures vary across environmental gradients, researchers can gain new insights into the extrinsic factors shaping social organization.

Environmental clines occurring along altitudinal and latitudinal gradients provide an ideal system in which 
to study the relationships between extrinsic ecological conditions and organism traits (Hodkinson 2005; Pellissier et al. 2012; Purcell 2011; Swenson \& Enquist 2007). Phenotype-environment covariation studies can be carried out both at the community level and within species. At the community level, we can ask whether species found in extreme environments exhibit different functional traits than those in clement environments. For instance, the proportion of ground nesting bee species increased significantly within increasing elevation in the Alps, while the proportion of primitively social bee species decreased (Hoiss et al. 2012; Kocher et al. 2014). Within species, we can identify phenotypic differences associated with environmental variation. For example, at the high-elevation range limit of the social spider species Anelosimus eximius, the spiders form smaller colonies and populations contain more solitaryliving females compared to populations in the lowland rainforest (Purcell \& Avilés 2007), suggesting that smaller group sizes are favoured at high elevation.

A major challenge in biogeographic studies of trait variation is to identify a sufficient number of phylogenetically independent contrasts. In other words, if a trait consistently varies along environmental clines, did the trait independently respond to the environment along each gradient or did the trait evolve once and spread through each Ecozone? If the trait responded independently along different gradients, this provides powerful evidence that some component of the environment consistently favours the trait of interest. In contrast, if the populations exhibiting alternative traits belong to separate evolutionary lineages, the effect of ecological factors is confounded with the phylogeographic history of the two forms, and the data set provides only one independent contrast. In the socially polymorphic bee Halictus rubicundus, for example, an initial survey found that high altitude and high latitude populations in western North America were all solitary, while lowland and lower latitude populations were primitively eusocial (Eickwort et al. 1996). However, the genetic structure of these populations demonstrated that the solitary populations were more closely related to one another than to the social populations, even when social and solitary populations occurred in close geographic proximity (Soucy \& Danforth 2002). Thus, the difference in social organization probably arose once in that region. European H. rubicundus populations show a different pattern, with social behaviour varying according to environmental conditions (Field et al. 2010). Such replicates in independent lineages are essential for a reliable identification of the ecological factors influencing a trait.

Studies of variation in social systems along latitudinal and altitudinal gradients have most often focused on species or taxa that are facultatively social, in the sense that the individual can live either solitary or in a social group (reviewed by Purcell 2011). The same approach can also be applied to understand the drivers of variation in social organization in taxa that only form social groups, such as ants and termites. Within these eusocial taxa, the groups often vary in social traits that affect how an organism interacts with its environment, including the number of nest founders, queen number and caste differentiation (Anderson \& McShea 2001).

In ants, polygyny (= colonies headed by two or more queens) evolved repeatedly from a monogynous, monandrous common ancestor (Hughes et al. 2008a,b). This transition in social organization is of particular interest because the presence of multiple queens lowers nestmate relatedness, which tends to reduce the inclusive fitness of workers (Keller 1995b). Polygyny may be adaptive under a range of conditions (Nonacs 1988), and several ecological hypotheses have been proposed to explain the transition from monogyny to polygyny (Bourke \& Franks 1995). First, polygyny may be advantageous in habitats where dispersal and independent colony founding are very risky, because queens of polygynous origin can join existing colonies, which is a safer option. Bourke \& Heinze (1994) proposed this 'ecological constraints' hypothesis to explain an increase in the occurrence of queen adoption and polygyny in high latitude and high altitude Leptothorax species (see also Heinze 1993; Heinze \& Rueppell 2014). Second, polygyny may be favoured in saturated environments, where nest-site limitation causes queens to join existing colonies (Ingram 2002; Pedersen \& Boomsma 1999). Third, the increased genetic diversity associated with multiple reproductives may increase the ability of a colony to resist pathogens (Keller 1995a; Schmid-Hempel \& Crozier 1999), or improve division of labour and colony homoeostasis (Jones et al. 2004).

Species that exhibit both monogyny and polygyny offer an ideal opportunity to explore the ecological factors underlying queen number variation. Here, we seek biogeographic patterns in the altitudinal distribution of colony queen number of a socially polymorphic ant species across multiple transects in geographically distant drainage basins. Our study species, the Alpine silver ant Formica selysi, exhibits a mix of monogynous and polygynous colonies within a single population (Chapuisat et al. 2004; Purcell \& Chapuisat 2013). As in other polymorphic species, each form is associated with a suite of behavioural and morphological traits (Keller 1993). In particular, queen and worker body sizes tend to be larger in monogynous than in polygynous colonies (Rosset \& Chapuisat 2007; Schwander et al. 2005), while the number of workers per colony is much smaller (Rosset \& Chapuisat 2007; Schwander et al. 2005). In 
the laboratory, brood growth rate also is faster in monogynous colonies (Purcell \& Chapuisat 2012). We have recently identified a 'social chromosome' associated with social organization, suggesting that some of these traits have a genetic basis (Purcell et al. 2014). These behavioural, morphological and genetic studies have been carried out in a single low-elevation population. So far, we did not know whether this species is polymorphic throughout its geographic and latitudinal range or whether one social form predominates in other habitats.

In this study, we investigate how the social structure of colonies varies across populations spanning multiple elevation gradients in Alpine valleys. We selected populations belonging to three major drainage basins, those of the Rhône, Po and Rhine Rivers, which drain to the western Mediterranean, Adriatic and North Seas, respectively. We address three questions. First, are populations more genetically differentiated by altitude (high elevation vs. low elevation) or by valley or drainage? This analysis reveals to which degree low and high populations from distinct drainage basins repre- sent independent contrasts. Second, are all F. selysi populations socially polymorphic? Third, is there a pattern in the distribution of each social form along the altitudinal gradient, and if so, what are the correlated environmental factors? In particular, we examine if polygynous colonies become more common at higher elevations, as documented in Leptothorax species (e.g. Bourke \& Heinze 1994; Heinze \& Rueppell 2014). The results of this study shed light on the forces maintaining this social polymorphism and, potentially, on the evolutionary history of this species. More broadly, this approach provides new insights into the ecological forces underlying the evolution of polygyny in ants.

\section{Methods}

\section{Field sampling}

We collected F. selysi workers from 209 colonies in 17 populations in Switzerland, northern Italy and eastern France (Table 1). These populations were distributed along elevation gradients in Alpine valleys from three

Table 1 Sampling locations, sample sizes and proportion of monogynous colonies

\begin{tabular}{|c|c|c|c|c|c|c|}
\hline Population name & Abbreviation & Valley & Drainage basin & Elevation & $\begin{array}{l}\text { \# Colonies } \\
\text { sampled }\end{array}$ & $\begin{array}{l}\text { \# Monogynous } \\
\text { colonies }\end{array}$ \\
\hline Les Bussets & a & $\begin{array}{l}\text { Durance, tributary of Rhône } \\
\text { River (Haute-Provence) }\end{array}$ & Mediterranean Sea & 644 & 8 & 4 \\
\hline Aigle & $\mathrm{N} / \mathrm{A}$ & Rhône River & Mediterranean Sea & 382 & 2 & 0 \\
\hline Riddes & $\mathrm{b}$ & Rhône River & Mediterranean Sea & 473 & 13 & 5 \\
\hline Derborence & c & $\begin{array}{l}\text { Derbonne, tributary of } \\
\text { Rhône River }\end{array}$ & Mediterranean Sea & 1420 & 40 & 30 \\
\hline Les Haudères & d & $\begin{array}{l}\text { Le Borgne, tributary of } \\
\text { Rhône River }\end{array}$ & Mediterranean Sea & 1455 & 10 & 7 \\
\hline La Luette & $\mathrm{e}$ & $\begin{array}{l}\text { Le Borgne, tributary of } \\
\text { Rhône River }\end{array}$ & Mediterranean Sea & 1045 & 4 & 0 \\
\hline Finges & $\mathrm{f}$ & Rhône River & Mediterranean Sea & 565 & $40^{*}$ & 24 \\
\hline Leuk & $\mathrm{g}$ & Rhône River & Mediterranean Sea & 631 & 16 & 13 \\
\hline Goms & $\mathrm{h}$ & Rhône River & Mediterranean Sea & 1290 & 4 & 0 \\
\hline Varzo & $\mathrm{i}$ & $\begin{array}{l}\text { Torrente Diviera, tributary of } \\
\text { Toce, Ticino and Po Rivers }\end{array}$ & Adriatic Sea & 495 & 8 & 3 \\
\hline Domodossola & $\mathrm{j}$ & $\begin{array}{l}\text { Toce River, tributary of } \\
\text { Ticino and Po Rivers }\end{array}$ & Adriatic Sea & 312 & 12 & 3 \\
\hline Maggia & $\mathrm{k}$ & $\begin{array}{l}\text { Maggia River, tributary of } \\
\text { Ticino and Po Rivers }\end{array}$ & Adriatic Sea & 305 & 12 & 4 \\
\hline Peccia & 1 & $\begin{array}{l}\text { Maggia River, tributary of } \\
\text { Ticino and Po Rivers }\end{array}$ & Adriatic Sea & 820 & 8 & 5 \\
\hline Fusio & $\mathrm{m}$ & $\begin{array}{l}\text { Maggia River, tributary of } \\
\text { Ticino and Po Rivers }\end{array}$ & Adriatic Sea & 1240 & 4 & 4 \\
\hline Arabella & $\mathrm{n}$ & $\begin{array}{l}\text { Moesa River, tributary of } \\
\text { Ticino and Po Rivers }\end{array}$ & Adriatic Sea & 472 & 4 & 2 \\
\hline Tamins & o & Rhine River & North Sea & 600 & 12 & 1 \\
\hline Safien & $\mathrm{p}$ & Rabiusa, tributary of Rhine River & North Sea & 1305 & 12 & 11 \\
\hline
\end{tabular}

*Randomly selected from a larger sample for biogeography comparison. 


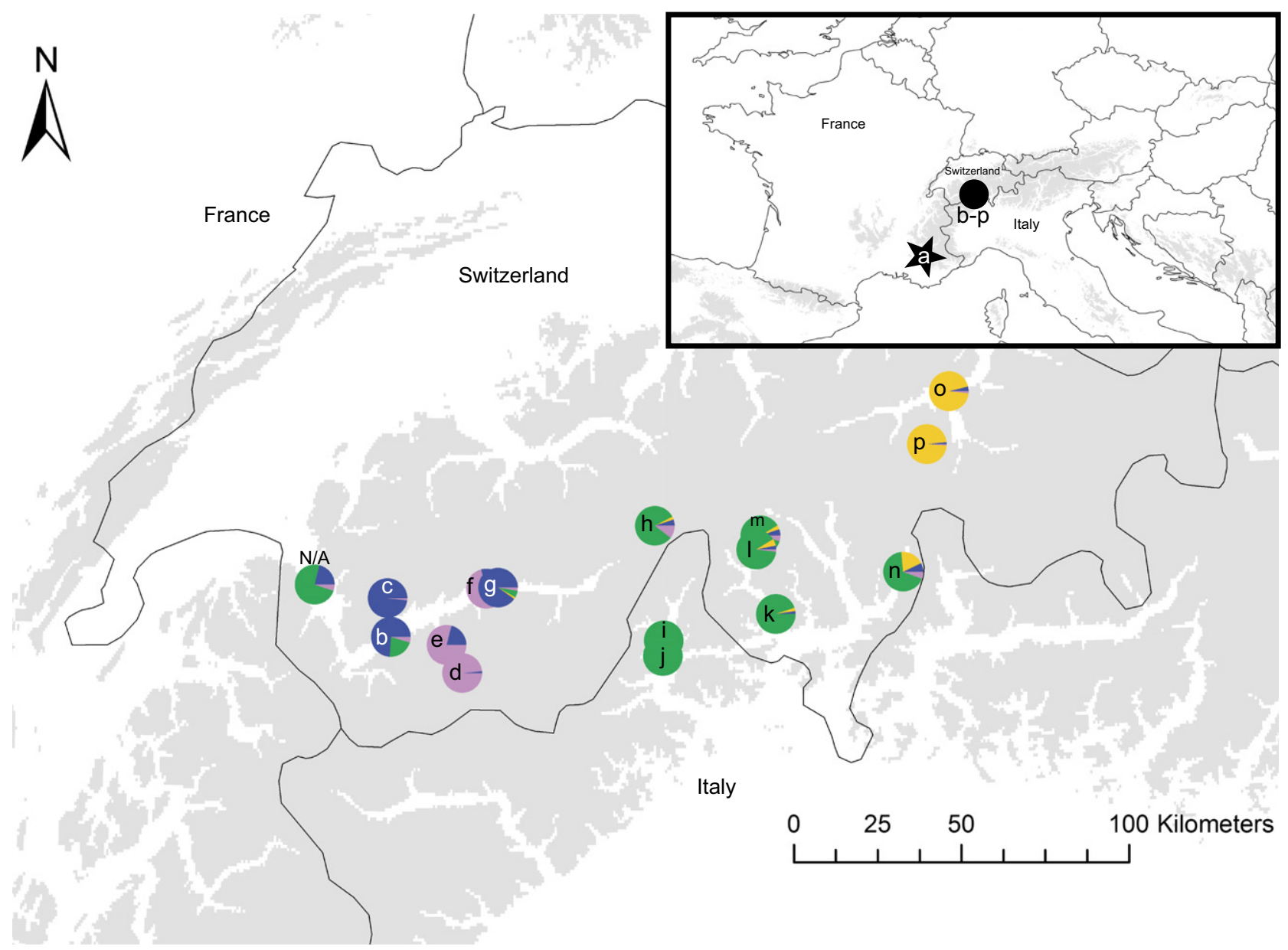

Fig. 1 Study area in the central Alps in Switzerland and northern Italy (inset, black circle), and in the southern Alps in Haute-Provence, France (star). Sampled populations in the Mediterranean, Adriatic and North Sea drainage basins are shown with pie charts representing the attribution of microsatellite genotypes from each population to four genetic clusters, as inferred from a microsatellite STRUCTURE analysis.

major drainage basins (Table 1, Fig. 1). We used a Garmin Oregon 650T global positioning system (GPS) to record the location of each colony with an accuracy of $\pm 10 \mathrm{~m}$.

\section{Environmental data preparation}

To obtain environmental information for each site, we prepared environmental data layers for the study area in ArcGIS (temperature of the coldest quarter, temperature of the warmest quarter, precipitation and flooding frequency). We obtained the climatic layers from WorldClim (Hijmans et al. 2005), which is based on measurements from meteorological stations. To produce more precise climatic information at each site, we downscaled WorldClim data from a 30 arc-second resolution to a $100 \mathrm{~m}$ resolution, using a digital elevation model as described in Engler et al. (2011). The flooding frequency layer was provided by the Swiss Federal Office for the Environment (FOEN) and thus applied only to populations in Switzerland $(\mathrm{N}=14)$.

\section{Genetic analyses}

We assessed the social structure of each colony by genotyping eight workers per colony at eight polymorphic microsatellite loci (Chapuisat et al. 2004; Purcell \& Chapuisat 2013). We performed a parentage analysis for each colony following Purcell \& Chapuisat (2013) to determine the minimum number of queens producing the workers, and we calculated the mean intracolony relatedness among workers using the computer program COANCESTRY (Wang 2011). We estimated the effective queen number ( $f$ ) from the relatedness values among workers $(r)$, using the following equation: 


$$
f=(3-r) /(3 r)
$$

This effective queen number reflects the number of queens per colony that would produce the observed degree of genetic relatedness among workers, assuming an idealized situation where queen number is stable, queens share reproduction equally, each queen mates with one unrelated male, and queens are as related as workers because they stay in their natal colony (Pamilo 1991).

We analysed the distribution of genetic differentiation above the colony level, to determine whether there was greater differentiation between low- and high-elevation colonies within drainages, or greater differentiation between drainage basins. The hierarchical F-analyses of variance were implemented in HIERFSTAT (Goudet 2005). Specifically, we used two separate four-level hierarchical analyses. In the first, individuals were nested within colonies, colonies within elevation (low or high), elevation within drainage basin and drainage basin within the total population. In the second analysis, individuals were nested within colonies, colonies within drainage basin, drainage basin within elevation and elevation within the total population. We also performed analyses with colony social organization as a variable (Appendix S1, Supporting information).

To further investigate patterns of genetic differentiation across populations from low and high altitude belonging to the same or different drainages, we identified genetic clusters with Bayesian clustering implemented in Structure 2.3.4 (Pritchard et al. 2010). We included the genotype at eight microsatellites from one haphazardly selected individual per colony across all colonies and populations. We used the admixture model setting and replicated the simulation 10 times for each $K$-value (2-10), with a burn-in period of 20000 followed by one million Markov Chain Monte Carlo iterations. We inferred the number of genetic clusters using the procedure of Evanno et al. (2005) and examined how the genotypes from each population were attributed to each genetic cluster. We analysed the data set with the LOCPRIOR model in STRUCTURE, which uses sampling locality as a prior (Hubisz et al. 2009). We did not include any information about membership of these collection localities in different drainages. Importantly, this approach does not tend to identify structure when none is present, and locality information is not used when the geographic information does not correlate with the ancestry of individuals (Hubisz et al. 2009).

In complement, we sequenced the mitochondrial gene COI from a sample of workers. We sequenced one worker per colony from at least two colonies from each of 16 populations (for primer information and PCR conditions, see Appendix S1, Supporting information). We constructed a haplotype network using TCS (Clement et al. 2000) to summarize the sequence differences among populations.

\section{Statistical tests of the association between social structure and environmental variables}

To test for an association between social structure (polygyny or monogyny) and environmental variables, we fit mixed effects models accounting for variation among drainages in the NLME package in R 3.0.2 ( $\mathrm{R}$ Core Team 2013). We tested whether social forms differ in their distribution with respect to elevation, average summer temperature, average winter temperature, average annual precipitation and flood frequency, with drainage basin as a random factor in each analysis. For polygynous colonies, we log-transformed effective queen number to normalize, and we investigated its association with the same environmental factors. These environmental measures are correlated with one another (see Fig. S2, Supporting information), so we analysed each one separately to avoid biases resulting from fixed factor order. We accounted for multiple comparisons by calculating false discovery rate $q$-values using the $q$-value package in $\mathrm{R}$.

\section{Results}

\section{Genetic structure}

We found that Formica selysi populations from separate drainages were genetically differentiated $\left(F_{\mathrm{ST}}\right.$ between drainages within the total population: 0.18 , 95\% confidence intervals $[0.12 ; 0.22] ; F_{\mathrm{ST}}$ between drainages within elevation: $0.22[0.17 ; 0.27])$. Populations from different drainages formed distinct clusters in the microsatellite STRUCTURE analysis and represented different mitochondrial lineages (Figs 1, 2A,B and S1, Supporting information). In contrast, low and high populations belonging to the same valley or drainage showed little genetic differentiation $\left(F_{\mathrm{ST}}\right.$ between low and high populations within drainages: 0.05 [0.03; 0.08], $F_{\mathrm{ST}}$ between elevation within the total population: -0.11 [-0.14; $-0.08]$; Table 1, Fig. 2A,B). There was very little genetic differentiation between monogynous and polygynous social forms at our eight microsatellite markers (Table S1, Supporting information).

In the assessment of population structure based on microsatellite genotypes implemented in STRUCTURE, the Evanno method (Evanno et al. 2005) revealed an optimal cluster number of four. Under these conditions $(K=4)$, the Rhône valley divided into two genetic clusters, with some introgression between them (Fig. 2B). When the number of clusters was set to three $(K=3)$, 
(A)

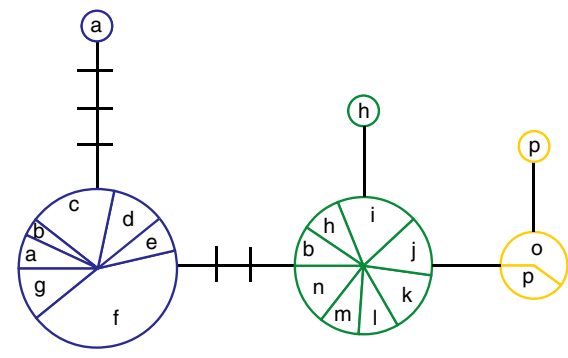

(B)

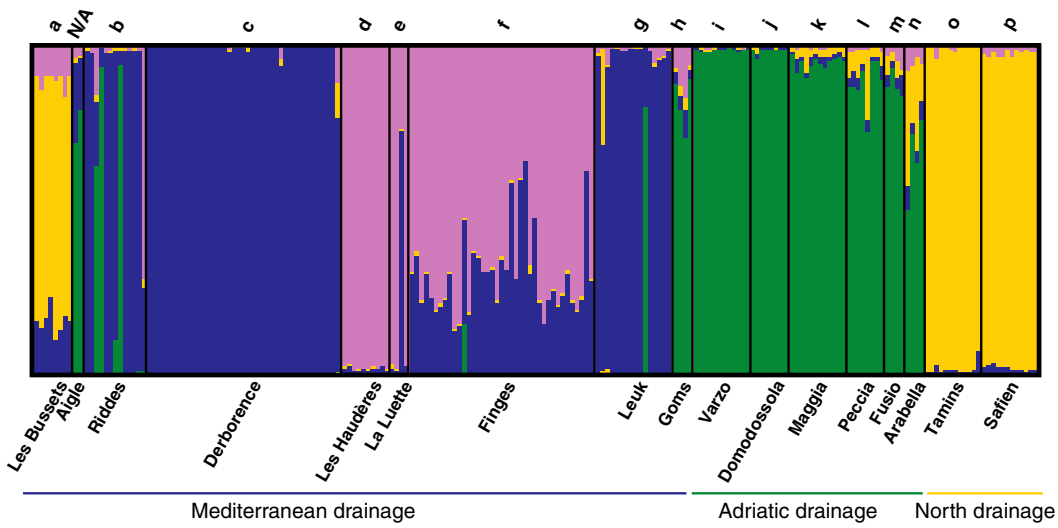

(C)

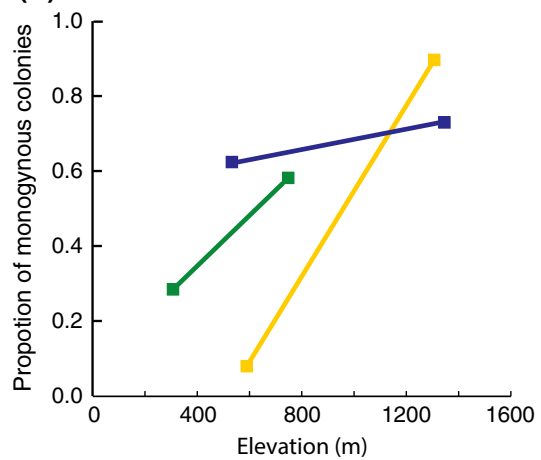

(D)

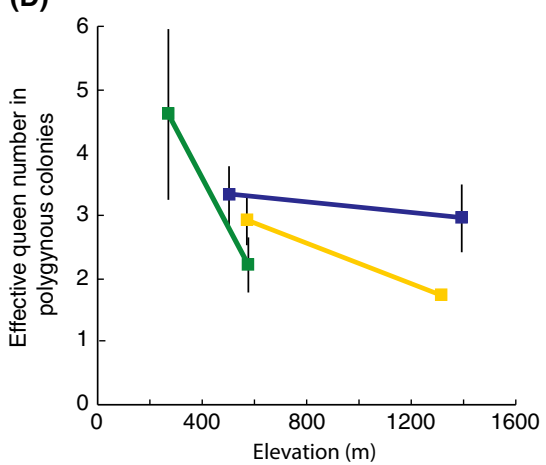

Fig. 2 Genetic structure (A, B) and variation in social structure with altitude within each genetic lineage (C, D). The genetic differentiation between populations is shown with a haplotype network for the mitochondrial gene COI (A) and with a STRUCTURE plot based on eight polymorphic microsatellite markers for one individual per sampled colony (B). Lower case letters designate different populations. In the haplotype network, each circle represents a unique haplotype, with the sizes proportional to the number of individuals. Haplotypes differing from each other by one base pair are separated by a single line, and ticks along the line represent additional base pair differences. In the STRUCTURE plot, each individual is represented in a column, clustered by population of origin. The colours represent inferred populations, and the proportion of each colour in a given column represents the proportion of the genome of an individual that originated from each inferred population. Within each of the three drainage basins and major genetic lineages, we find a consistent and significant increase in the proportion of monogynous colonies (C) and a decreasing trend in the effective queen number within polygynous colonies (D) at higher elevations. For these illustrative plots (C and D), we calculated the proportion of monogynous colonies (C) and the average effective queen number (D) for all low-elevation and all high-elevation populations from each drainage, with the average elevation of populations in each category displayed. We excluded the 14 individuals from the Mediterranean Sea drainage that had a genetic background corresponding primarily to the green or yellow inferred population. Black lines show standard error for the effective queen number (D).

the genetic clusters approximately corresponded to the Mediterranean, Adriatic and North Sea drainage basins (Fig. S1, Supporting information).

We also identified three major mitochondrial lineages. One lineage predominated in the Mediterranean drainage, one in the Adriatic drainage and the third one, an offshoot of this Adriatic drainage haplotype, was present in the North Sea drainage (Fig. 2A).

Together, these data indicate that $F$. selysi forms distinct genetic lineages in distantly located valleys belonging to separate drainages, but not between populations occupying low- and high-altitudinal Ecozones within 
the same valleys or drainages. Hence, altitudinal transects in separate genetic clusters or drainages represent independent contrasts where we can test for an association between social structure and environmental conditions.

\section{Social structure variation and association with altitude}

All the populations in which we sampled more than four colonies were socially polymorphic, exhibiting both monogynous and polygynous colonies (Table 1). Contrary to our expectation, the proportion of monogynous colonies increased consistently at higher elevation, and this pattern was replicated in each of the three drainage basins (Mixed effects model: $F_{1,205}=13.1, P<0.001$, $q=0.003$; Fig. 2C). This pattern was significantly associated with both summer and winter temperature $\left(F_{1}\right.$, $205=13.1, P<0.001, q=0.003 ; F_{1,205}=12.2, P<0.001$, $q=0.003$, respectively), but not with precipitation $\left(F_{1}\right.$, $205=3.73, P=0.06, q=0.09)$ or the frequency of flooding events $\left(F_{1,177}=1.99, P=0.16, q=0.20\right)$.

Within polygynous colonies, the effective queen number $(f)$ tended to decrease with rising elevation, and this trend was observed in each of the drainages (Fig. 2D). The mixed models revealed no significant association between effective queen number and elevation $\left(F_{1,79}=\right.$ 2.50, $P=0.12, q=0.09)$, summer temperature $\left(F_{1,79}=\right.$ 2.74, $P=0.10, q=0.09)$ or precipitation $\left(F_{1,79}=0.18\right.$, $P=0.67, q=0.60)$. However, effective queen number was significantly associated with both winter temperature $\left(F_{1}, 79=4.54, P=0.04, q=0.07\right)$ and flood frequency $\left(F_{1}, 65=4.54, P=0.04, q=0.07\right)$, with fewer queens occurring in habitats with colder winters and more frequent floods.

\section{Discussion}

Using a spatial ecology approach to detect intraspecific variation in social structure along environmental gradients, we gain insights into the ecological factors influencing a social polymorphism. In the ant Formica selysi, all well-sampled populations distributed across Alpine valleys from three drainages are socially polymorphic, containing both monogynous and polygynous colonies. However, the proportion of monogynous colonies within populations increases with rising elevation, while the effective number of queens in polygynous colonies tends to decrease. This association between monogyny and high elevation is replicated across three river drainages containing distinct genetic lineages.

\section{Population structure}

The F. selysi populations belonging to different drainage basins are genetically differentiated. The hierarchical
$F$-analyses of variance reveal significant genetic differentiation among drainage basins. The analysis of microsatellite markers with the program STRUCTURE further reveals four genetic clusters, one in the Adriatic drainage, one in the North Sea drainage and two in the Mediterranean drainage. Moreover, the populations from the central Alps exhibit three major mitochondrial haplotypes, which also correspond to the three major drainage basins. These genetic data indicate that $F$. selysi is divided into lineages with a recent history of independent evolution. If we assume a COI molecular clock of $1-2 \% / \mathrm{My}$ as observed in other invertebrates (e.g. Wilke et al. 2009), the divergence between the lineages occupying the Mediterranean and Adriatic Sea drainages $(0.37 \%)$, as well as the Adriatic and North Sea drainages $(0.13 \%)$, are consistent with the possibility that the species has persisted in separate refugia during the Pleistocene glaciations. Within each genetic lineage, populations at low and high elevation exhibit little differentiation, such that low- and high-elevation populations in each drainage basin represent independent contrasts. Hence, studying intraspecific variation along elevation gradients in three drainage basins provides a powerful set of independent tests of the influence of ecological conditions on social structure.

\section{Social polymorphism across populations}

All well-sampled populations contained both monogynous and polygynous colonies. This contrasts with many other socially polymorphic ant species, like Solenopsis invicta or Formica exsecta, where each social form occurs within spatially segregated populations (e.g. Ross \& Keller 1995; Seppä et al. 2004). This finding is particularly interesting in the light of the recent discovery of a large, nonrecombining social chromosome associated with queen number variation in this species (Purcell et al. 2014). With such a strong genetic basis of social organization identified in one well-sampled population, it is unlikely that phenotypic plasticity alone maintains the variation in social organization along elevation gradients.

Given the putative genetic control of queen number in F. selysi, what factors contribute to the maintenance of this widespread polymorphism? A genetic polymorphism may be maintained by frequency dependent selection, fitness variation in space and time, or other forms of balancing selection (e.g. Fitzpatrick et al. 2007; Richman 2000). In F. selysi, ecological factors are expected to contribute to the maintenance of social structure polymorphism. Our results show that the two social forms differ in the average ecological conditions that they experience. If each form has a different ecological optimum, this could contribute to the maintenance of the social polymorphism in this species. 
The systematic co-occurrence of the two social forms in each population requires additional explanation. There could be local variation in ecological conditions favouring one or the other social form at a small spatial scale. In particular, the queens of the two social forms of F. selysi are probably differ in dispersal and colonization ability. This is expected because queens produced by monogynous colonies are larger (Meunier \& Chapuisat 2009; Rosset \& Chapuisat 2007), and in ants, larger monogynous queens are generally superior dispersers and nest foundresses, while smaller polygynous queens tend to stay in their natal nest and may be better at monopolizing local patches of habitat (reviewed by Ross \& Keller 1995). These tendencies may result in a fugitive coexistence dynamic, wherein F. selysi queens from monogynous colonies are better able to colonize locally disturbed habitat and polygynous colonies maintain a competitive advantage in more stable and continuous habitat (Armstrong 1976). Floodplains comprise the primary habitat for all F. selysi populations. The social polymorphism therefore could be maintained by periodic flood events that cause erosion and open up new habitat.

Nonecological factors could also contribute to maintaining the polymorphism at a local scale. For example, co-occurrence of the two social forms is expected if they are genetically interdependent, for example if queens of one social form benefit from mating with males from the other. Extreme examples of such genetic interdependence are found in Pogonomyrmex species, where interlineage crosses produce workers while intralineage crosses produce queens (Schwander et al. 2007).

\section{Queen number variation along elevation gradients}

The decreases in the proportion of polygynous colonies and in the effective queen number within polygynous colonies at higher elevation were correlated with reduced temperatures, but not with precipitation. Importantly, both growing season length and habitat productivity tend to be correlated with temperature variation (Körner 2007). Snow cover and slope are also likely to vary with both elevation and temperature, which may further affect the ants' annual cycle. We propose two nonmutually exclusive hypotheses to explain the distribution of social structures along elevation gradients and explore each in more detail below. First, each social form may have distinct ecological constraints, and differences along elevation gradients may affect their distribution. Second, habitat at the high-elevation range limit of the species may represent a population sink, and differential dispersal abilities may shape the distribution of colony types.

Differences in ecological conditions, resource availability and habitat stability could affect each of the social forms differently, thereby shaping their distributions. For example, at higher elevation, the colder environment and shorter growing seasons may favour the form with a faster development time (Kocher et al. 2014). In a recent cross-fostering experiment, we found that brood of monogynous origin completes development slightly faster than brood of polygynous origin, regardless of the identity of the rearing workers (Purcell \& Chapuisat 2012), which might contribute to the increased prevalence of this social form at higher elevation.

More generally, polygynous colonies of F. selysi could perform better in stable, continuous and resource rich environments, where habitats are more likely to become saturated and where the greater availability of resources is able to support their larger colonies (Rosset \& Chapuisat 2007; habitat saturation hypothesis: e.g. Pedersen \& Boomsma 1999). Conversely, monogynous colonies would have an advantage in temporally unpredictable environments, where producing larger numbers of sexual offspring each year could ensure propagation in more variable, patchy and resource poor environments.

In parallel to the decrease in the proportion of polygynous colonies, the effective number of queens within polygynous colonies tended to decrease in colder environments. It is thus possible that the ecological conditions favouring monogyny also select for a reduced number of queens in polygynous colonies. Polygynous colonies may acquire fewer additional queens in harsher environments, which could be linked to a smaller colony size or younger colony age. Alternatively, this pattern of decreasing effective queen number may be driven by an increase in the inbreeding level within polygynous colonies at higher elevations.

It is interesting to note that $F$. selysi is responding differently to environmental pressures that the Leptothorax species living in extreme northern environments and Temnothorax rugatulus populations at high elevation, where queen number tended to increase in harsher conditions, possibly in response to higher dispersal and colony founding risks (Bourke \& Heinze 1994; Heinze 1993; Heinze \& Rueppell 2014). Many differences between the systems could explain this contrasting response. For example, Leptothorax ants nest in natural cavities (in twigs, bark or under stones) whereas Formica selysi dig their nests in the soil. The former strategy is more likely to be susceptible to constraints due to nest-site limitation when vegetation is sparse.

An alternative hypothesis to explain the altitudinal distribution of social structure in F. selysi is that lowand high-elevation sites exhibit source-sink dynamics or even extinction-recolonization dynamics. If high-elevation habitats are marginal for this species, we would expect to see ongoing, unidirectional gene flow from 
lower elevation habitats. In this case, assuming that the larger, heavier alate queens from monogynous colonies are better dispersers and colony foundresses than their counterparts from polygynous colonies, we would expect to find the observed pattern, with a higher proportion of monogynous colonies in high-elevation sink environments. Consistent with this hypothesis, the high-elevation populations in each valley exhibited a very low degree of genetic differentiation from low-elevation populations (Fig. 2B).

\section{Conclusions}

Overall, our detailed investigation of intraspecific social structure variation along elevation gradients in the Alpine silver ant reveals that all populations are socially polymorphic and that colonies with simpler family structure (i.e. monogynous or containing only few queens) become more abundant in cold, high-elevation environments. This shift in social structure occurs in parallel in three drainage basins containing independent genetic lineages, which suggests that this pattern is unlikely to be due to drift. Rather, selection or an environmental filtering process is probably at work. The finding that polygynous colonies are less common at high elevations is not consistent with the ecological constraints hypothesis, which suggests that queen adoption should be favoured in risky environments (Bourke \& Heinze 1994). The observed pattern could be explained by differential success of each social form in low- vs. high-elevation environments or could result from nonadaptive processes, such as source-sink dynamics. Overall, this system of replicated, genetically independent lineages that exhibit consistent variation along elevation gradients provides an ideal venue for direct tests of how abiotic and biotic factors contribute to the evolution and maintenance of polygyny and social polymorphism.

\section{Acknowledgements}

We thank Geneviève Metthez for her assistance in the laboratory, and Alan Brelsford and three anonymous reviewers for input on the manuscript. This project was funded by Swiss National Science Foundation grants 31003A-125306 and 31003A-146641 to MC.

\section{References}

Anderson C, McShea DW (2001) Individual vs. social complexity, with particular reference to ant colonies. Biological Reviews, 76, 211-237.

Armstrong RA (1976) Fugitive species: experiments with fungi and some theoretical considerations. Ecology, 57, 953-963.

Bourke AFG (2011) Principles of Social Evolution. Oxford University Press, Oxford.
Bourke AFG, Franks NR (1995) Social Evolution in Ants. Princeton University Press, Princeton, NJ

Bourke AFG, Heinze J (1994) The ecology of communal breeding: the case of multiple-queen leptothoracine ants. Philosophical Transactions of the Royal Society B-Biological Sciences, 345, 359-372.

Chapuisat M, Bocherens S, Rosset H (2004) Variable queen number in ant colonies: no impact on queen turnover, inbreeding, and population genetic differentiation in the ant Formica selysi. Evolution, 58, 1064-1072.

Clement M, Posada D, Crandall KA (2000) TCS: a computer program to estimate gene genealogies. Molecular Ecology, 9, 1657-1659.

Eickwort GC, Eickwort JM, Gordon J, Eickwort MA (1996) Solitary behavior in a high altitude population of the social sweat bee Halictus rubicundus (Hymenoptera: Halictidae). Behavioral Ecology and Sociobiology, 38, 227-233.

Engler R, Randin CF, Thuiller W et al. (2011) 21st century climate change threatens mountain flora unequally across Europe. Global Change Biology, 17, 2330-2341.

Evanno G, Regnaut S, Goudet J (2005) Detecting the number of clusters of individuals using the software STRUCTURE: a simulation study. Molecular Ecology, 14, 2611-2620.

Field J, Paxton RJ, Soro A, Bridge C (2010) Cryptic plasticity underlies a major evolutionary transition. Current Biology, 20, 2028-2031.

Fitzpatrick MJ, Feder E, Rowe L, Sokolowski MB (2007) Maintaining a behaviour polymorphism by frequency-dependent selection on a single gene. Nature, 447, 210-212.

Goudet J (2005) HIERFSTAT, a package for R to compute and test hierarchical F-statistics. Molecular Ecology Notes, 5, 184-186.

Heinze J (1993) Life histories of subarctic ants. Arctic, 46, 354-358.

Heinze J, Rueppell O (2014) The frequency of multi-queen colonies increases with altitude in a Nearctic ant. Ecological Entomology, 39, 527-529.

Hijmans RJ, Cameron SE, Parra JL, Jones PG, Jarvis A (2005) Very high resolution interpolated climate surfaces for global land areas. International Journal of Climatology, 25, 1965-1978.

Hodkinson ID (2005) Terrestrial insects along elevation gradients: species and community responses to altitude. Biological Reviews, 80, 489-513.

Hoiss B, Krauss J, Potts SG, Roberts S, Steffan-Dewenter I (2012) Altitude acts as an environmental filter on phylogenetic composition, traits and diversity in bee communities. Proceedings of the Royal Society B: Biological Sciences, 279, 4447-4456.

Hubisz MJ, Falush D, Stephens M, Pritchard JK (2009) Inferring weak population structure with the assistance of sample group information. Molecular Ecology Resources, 9, 1322-1332.

Hughes WOH, Oldroyd BP, Beekman M, Ratnieks FLW (2008a) Ancestral monogamy shows kin selection is key to the evolution of eusociality. Science, 320, 1213-1216.

Hughes WOH, Ratnieks FLW, Oldroyd BP (2008b) Multiple paternity or multiple queens: two routes to greater intracolonial genetic diversity in the eusocial Hymenoptera. Journal of Evolutionary Biology, 21, 1090-1095.

Ingram KK (2002) Plasticity in queen number and social structure in the invasive Argentine ant (Linepithema humile). Evolution, 56, 2008-2016.

Jones JC, Myerscough MR, Graham S, Oldroyd BP (2004) Honey bee nest thermoregulation: diversity promotes stability. Science, 305, 402-404. 
Keller L (1993) Queen Number and Sociality in Insects, p. 439. Oxford University Press, Oxford.

Keller L (1995a) Parasites, worker polymorphism, and queen number in social insects. American Naturalist, 145, 842-847.

Keller L (1995b) Social life: the paradox of multiple-queen colonies. Trends in Ecology and Evolution, 10, 355-360.

Kocher SD, Pellissier L, Veller C et al. (2014) Transitions in social complexity along altitudinal gradients reveal a combined impact of season length and development time on social evolution. Proceedings of the Royal Society B: Biological Sciences, 281, 20140627.

Körner C (2007) The use of 'altitude' in ecological research. Trends in Ecology and Evolution, 22, 569-574.

Meunier J, Chapuisat M (2009) The determinants of queen size in a socially polymorphic ant. Journal of Evolutionary Biology, 22, 1906-1913.

Nonacs P (1988) Queen number in colonies of social Hymenoptera as a kin-selected adaptation. Evolution, 42, 566-580.

Pamilo P (1991) Evolution of colony characteristics in social insects. II. Number of reproductive individuals. American Naturalist, 138, 412-433.

Pedersen JS, Boomsma JJ (1999) Effect of habitat saturation on the number and turnover of queens in the polygynous ant, Myrmica sulcinodis. Journal of Evolutionary Biology, 12, 903-917.

Pellissier L, Fiedler K, Ndribe C et al. (2012) Shifts in species richness, herbivore specialization, and plant resistance along elevation gradients. Ecology and Evolution, 2, 1818-1825.

Pritchard J, Wen X, Falush D (2010) Structure version 2.3.3.

Purcell J (2011) Geographic patterns in the distribution of social systems in terrestrial arthropods. Biological Reviews, 86, 475-491.

Purcell J, Avilés L (2007) Smaller colonies and more solitary living mark higher elevation populations of a social spider. Journal of Animal Ecology, 76, 590-597.

Purcell J, Chapuisat M (2012) The influence of social structure on brood survival and development in a socially polymorphic ant: insights from a cross-fostering experiment. Journal of Evolutionary Biology, 25, 2288-2297.

Purcell J, Chapuisat M (2013) Bidirectional shifts in colony queen number in a socially polymorphic ant population. Evolution, 67, 1169-1180.

Purcell J, Brelsford A, Wurm Y, Perrin N, Chapuisat M (2014) Convergent genetic architecture underlies social organization in ants. Current Biology, 24, 2728-2732.

R Core Team (2013) R: A Language and Environment for Statistical Computing, R Foundation for Statistical Computing, Vienna, Austria. Available from http://www.R-project.org/.

Richman A (2000) Evolution of balanced genetic polymorphism. Molecular Ecology, 9, 1953-1963.

Ross KG (2001) Molecular ecology of social behaviour: analyses of breeding systems and genetic structure. Molecular Ecology, 10, 265-284.

Ross KG, Keller L (1995) Ecology and evolution of social organization: insights from fire ants and other highly eusocial insects. Annual Review of Ecology and Systematics, 26, 631-656.

Rosset H, Chapuisat M (2007) Alternative life-histories in a socially polymorphic ant. Evolutionary Ecology, 21, 577-588.

Schmid-Hempel P, Crozier RH (1999) Polyandry vs. polygyny vs. parasites. Philosophical Transactions of the Royal Society BBiological Sciences, 354, 507-515.
Schwander T, Rosset H, Chapuisat M (2005) Division of labour and worker size polymorphism in ant colonies: the impact of social and genetic factors. Behavioral Ecology and Sociobiology, 59, 215-221.

Schwander T, Keller L, Cahan SH (2007) Two alternate mechanisms contribute to the persistence of interdependent lineages in Pogonomyrmex harvester ants. Molecular Ecology, 16, 3533-3543.

Seppä P, Gyllenstrand M, Corander J, Pamilo P (2004) Coexistence of the social types: genetic population structure in the ant Formica exsecta. Evolution, 58, 2462-2471.

Soucy SL, Danforth BN (2002) Phylogeography of the socially polymorphic sweat bee Halictus rubicundus (Hymenoptera: Halictidae). Evolution, 56, 330-341.

Swenson NG, Enquist BJ (2007) Ecological and evolutionary determinants of a key plant functional trait: wood density and its community-wide variation across latitude and elevation. American Journal of Botany, 94, 451-459.

Wang J (2011) COANCESTRY: a program for simulating, estimating and analysing relatedness and inbreeding coefficients. Molecular Ecology Resources, 11, 141-145.

Wilke T, Schultheiss R, Albrecht C (2009) As time goes by: a simple fool's guide to molecular clock approaches in invertebrates. American Malacological Bulletin, 27, 25-45.

J.P. designed the study, performed the field and lab work, and analyzed the data. L.P. contributed the environmental data and provided input on data analysis. M.C. provided input on population genetic analysis. J.P. drafted the manuscript with improvements added by L.P. and M.C.

\section{Data accessibility}

COI sequences are archived on GenBank, Accession nos KP164416-KP164473.

Files containing aligned COI sequences; Queen number, sampling location and climatic data; and microsatellite genotypes are archived on Dryad, DOI: 10.5061/ dryad.6d4n6.

\section{Supporting information}

Additional supporting information may be found in the online version of this article.

Appendix S1 COI primer info and PCR conditions.

Fig. S1 Structure plot, $K=3$.

Fig. S2 Correlations among environmental variables.

Table S1 Results of HierFstat models. 